\title{
Chordoma Sociodemographic, Clinical and Therapeutic Aspects in National Institute of Oncology Rabat Morocco: A Report of 9 Cases
}

\author{
Gaël Kietga, Patricia Agbanglanon, Bertrand Compaore, Evrard Seka, Amine Lachgar, \\ Noureddine Benjaafar
}

Radiation Therapy Department, National Institute of Oncology Rabat, Rabat, Morocco

Email: gaelkietga@yahoo.fr

How to cite this paper: Kietga, G., Agbanglanon, P., Compaore, B., Seka, E., Lachgar, A. and Benjaafar, N. (2021) Chordoma Sociodemographic, Clinical and Therapeutic Aspects in National Institute of Oncology Rabat Morocco: A Report of 9 Cases. Journal of Cancer Therapy, 12, 47-56. https://doi.org/10.4236/jct.2021.121005

Received: November 15, 2020

Accepted: January 17, 2021

Published: January 20, 2021

Copyright $\odot 2021$ by author(s) and Scientific Research Publishing Inc. This work is licensed under the Creative Commons Attribution International License (CC BY 4.0).

http://creativecommons.org/licenses/by/4.0/

\section{(c) (i) Open Access}

\begin{abstract}
Introduction: Chordoma is a rare bone tumor, which develops mainly from the sacrum, the base of the skull, or the spine. Surgery + radiotherapy (if necessary) is the standard treatment. Data on chordoma are scarce in this region, and thus, here we summarized 9 patients with this tumor whom we treated in this institute. Material: Nine chordoma patients were summarized, who were treated in National Institute of Oncology in Rabat between 2013 and 2018. We retrieved data from medical charts and analyzed the clinical characteristics of this tumor. Results: The average age was 49 years (range: 29 - 72), with male: female of 3:6. The manifestation-diagnosis time was 4 months (range: 2 - 14). Regarding the tumor location, lumbosacral spine; 5, the skull; 4. Mass was evident in 6. Signs of locoregional compressions (paraparesis or tetraparesis) were observed in 3. As for treatment, a partial tumor excision was performed in 8 , with 3 patients undergoing a wide excision. Radiotherapy was done; 3 patients with a dose of $46 \mathrm{~Gy}, 3$ patients with $66 \mathrm{~Gy}, 1$ patient with $50 \mathrm{~Gy}$, and 1 patient with a 16 Gy gamma radio-knife in a single session. 4 patients with a dose of $46 \mathrm{~Gy}, 2$ patients with $60 \mathrm{~Gy}$, and 1 patient with a 16 Gy gamma radio-knife in a single session. Of 9, 4 patients had good locoregional control whereas 5 patients had local recurrence. Conclusion: Chordoma is a predominantly local aggressive tumor with low metastatic potential. The surgical excision remains the main prognostic factor. Advances in radiotherapy may improve local control. These data are of use in management of this tumor in Rabat (Morocco).
\end{abstract}

\section{Keywords}

Chordoma, Diagnosis, Radiation Therapy, Morocco 


\section{Introduction}

Chordoma is a rare primary bone malignancy representing $1 \%-4 \%$ of malignant bone tumors [1] [2]; chordomas arise from remnants of the notochord; they develop in the skull base and spine. They characteristically occur in adults with a peak of incidence in the sixth and seventh decades [3].

Chordomas are indolent and slow growing, therefore they are often clinically silent until the late stages of disease. The clinical manifestations vary and depend on location and on their size [4]. CT and MR Imaging are not features specific of chordoma. The relative rarity of these tumors, combined with their biological heterogeneity, pose diagnostic challenges to pathologists. Chordomas are characterised by their local malignant potential, his high rate of recurrence and his poor prognostic.

\section{Aims}

Describe the clinical, radiological, therapeutic and evolutionary aspects of chordomas at the National Institute of Oncology (INO) and conduct a literature review.

\section{Patients and Methods}

This was a retrospective study that was conducted at the radiotherapy department at the National Oncology Institute Rabat Morocco with 09 cases of chordoma in the period from January 2013 to December 2018.

Patients characteristics (age, sex, clinical and radiological data (MRI, CTscan)) were collected from medical records. Diagnoses were confirmed by an anatomopathological examination with an immunohistochemical test of the biopsy or excisional material. All patients who received radiotherapy after surgery were included in our study series. 01 patient death before radiotherapy were also included in our study serie.

\section{Ethical Committee Approval}

Approval of radiotherapy department of national institute of oncology were obtained. No individual patient consent was needed as the study poses no risk of harm to any of the study subjects that you have the correct template for your paper size. is customary. This measurement and others are deliberate, using specifications that anticipate your paper as one part of the entire journals, and not as an independent document. Please do not revise any of the current designations.

\section{Results}

This study included 09 patients with chordoma. Their mean age was 49 years. (Table 1): Male to female ratio was about 3:6. The average consultation time was 04 months [2 - 14]. The chordoma site was brain in 3 cases (33\%) and spinal cord in 6 cases $(67 \%)$. 
Table 1. Sociodemographic, clinical and therapeutic characteristics of patients with chordomas.

\begin{tabular}{|c|c|c|c|c|c|}
\hline \multirow{2}{*}{ Number } & \multicolumn{5}{|c|}{ Characteristics } \\
\hline & Age & Sex & Location & Clinical Signs and Imaging & Treatment \\
\hline 1 & 50 & Female & Sacrum & $\begin{array}{l}\text { S2-S3 Paraparesis } \\
\text { Anal incontinence }\end{array}$ & $\begin{array}{c}\text { Sacrum surgery + Radiotherapy } \\
66 \text { Gy or } 33 \text { sessions of } 2 \mathrm{~Gy}\end{array}$ \\
\hline 2 & 50 & Female & Sella turcica & optic chiasma syndrome & Partial surgery + Radiotherapy 16 Gy \\
\hline 3 & 42 & Female & Sacral coccyx & Intergluteal mass & Block resection + RTH Sacrum 50 Gy \\
\hline 4 & 49 & Female & Fronto-parietal & callosum process mass & Death before treatment \\
\hline 5 & 70 & Male & Sacrum & $\begin{array}{l}\text { Sacrum mass } \\
\text { Urinary incontinence }\end{array}$ & Partial surgery + radiotherapy 66 Gy \\
\hline 6 & 40 & Female & Lumbar L4 & Paraparesis & Partial surgery + Radiotherapy 46 Gy \\
\hline 7 & 58 & Male & Cervical & Tetraparesis & Partial surgery + Radiotherapy 46 Gy \\
\hline 8 & 29 & Male & Clivus & Clivus mass & Partial surgery + Radiotherapy 46 Gy \\
\hline 9 & 72 & Female & Lumbar L4 & Lumbar mass & $\begin{array}{l}\text { Lumbar decompression surgery } \\
\text { + Radiotherapy } 66 \mathrm{~Gy}\end{array}$ \\
\hline
\end{tabular}

The main clinical features from brain chordoma were optic chiasma signs (01 case), frontoparietal mass ( 01 case), and clivus mass (01 case). The main clinical features from spine chordomas were para paresis (02 cases), tetraparesis (01 case) intergluteal mass (01 case) lumbar mass (01 case), urinary incontinence and sacrum mass (01 case). The diagnosis of chordoma was made by anatomo-pathology and confirmed by immunohistochemistry.

CT scan was performed only for 06 patients and MR Imaging only on three patients. CT revealed soft tissue masses were mainly presented (Figure 1). MR imaging revealed heteregeneous signal intensity and well-defined tumor (Figure 2).

In our series, 01 patient death before the treatment; 8 patients underwent a partial resection, 3 of whom underwent a wide resection. These 8 patients had received adjuvant radiotherapy. 3 patients with a dose of $46 \mathrm{~Gy}, 3$ patients with $66 \mathrm{~Gy}, 1$ patient with $50 \mathrm{~Gy}$, and 1 patient with a $16 \mathrm{~Gy}$ gamma radio-knife in a single session. These patients were irradiated with External Beam Radiation Therapy (EBRT). The average dose was $50 \mathrm{~Gy}$ [46 - $66 \mathrm{~Gy}$ ] 2 Gy/fractions, with an average of 25 sessions and an average spread of 58 days (43 - 62) (Table 1). No acute toxicity was observed in our series of studies. The long-term evolution after 20 months was marked by good disease control for four patients, and for four patients by locoregional reccurence. The limitations of our study include the small sample size, its retrospective nature over long period, cases were from a single hospital. 

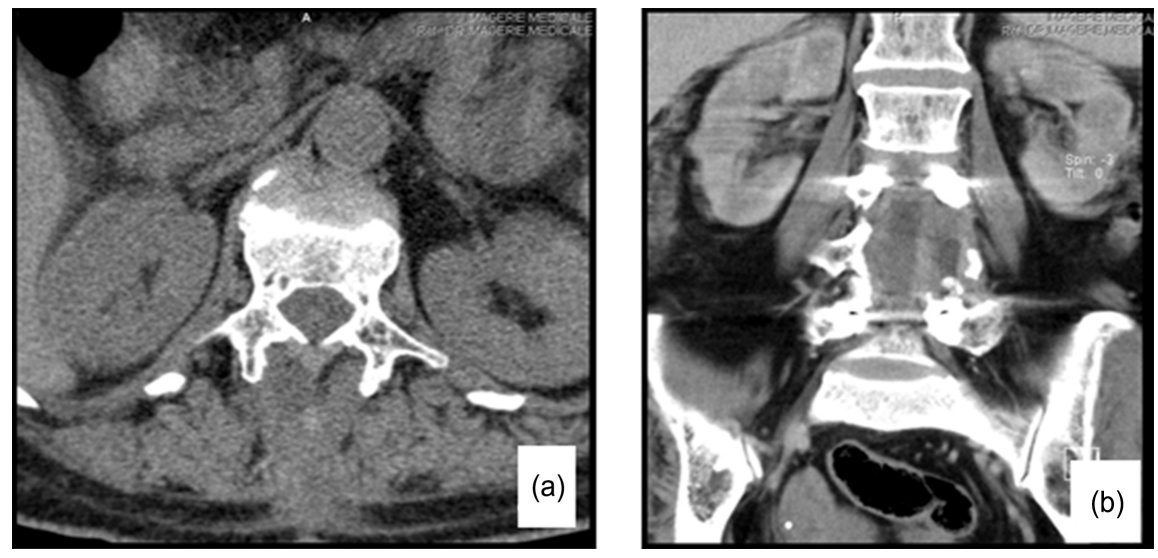

Figure 1. CT image lytic bone lumbar L4 chordoma. (a) Transversal view; (b) Frontal view.
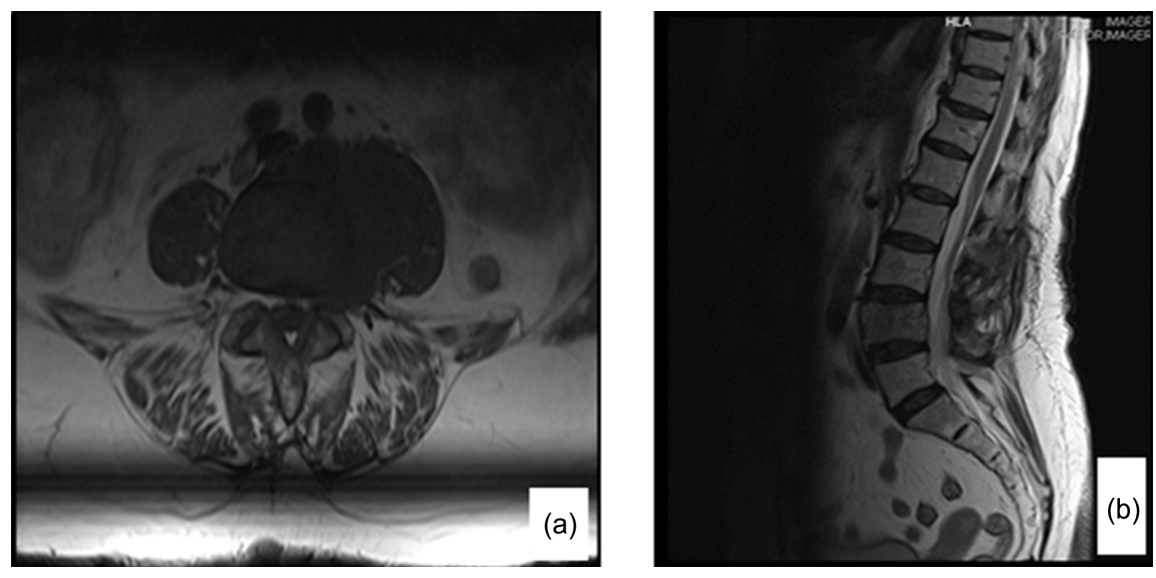

Figure 2. MRI lytic image bone Lumbar L4 chordoma. (a) Transversal view; (b) Lateral view.

\section{Discussion}

Chordoma is a rare subtype of bone sarcoma, exhibiting notochordal differentiation. The incidence rate of approximately 0.8 per million persons per year reported for the US studies making use of the SEER registry but the European and Taiwanese studies show incidence rates ranging from 0.18 to 0.52 per million persons per year [5] [6] [7] [8]. Chordoma representing 1\% - 4\% of malignant bone tumors [1] [2]. Population studies in the United States according to the database SEER found an average age of 50 to 60 years for patients with chordoma with a male predominance [6] [7]. In our series, the average age was young at 49: range: 29 - 72 years. Müller [9] was first to suggest in 1858 that these tumours may be of notochordal origin. In humans, most notochordal remnants disappear during the first years of life [10]. By a mechanism still unknown, in some people notochordal tissue remains along the axial skeleton, which explains the locations where chordoma occurs: the bulk arises at the sacrum or clivus and the remainder occur at varying levels of the mobile spine. However, not every remnant of notochord transforms into chordoma [5]. As for chordoma primary 
site distribution, $33 \%$ of chordoma cases are spinal, $32 \%$ cranial, $29 \%$ sacral and $6 \%$ have other primary sites [6] [11]. Exceptional locations have been described, in particular in the eye sockets, sinuses, or scapula [12]. In our series, the lumbosacral location was found for 4 patients (44\%) and the spinal location for 5 patients $(66 \%)$.

Chordomas are indolent and slow growing, therefore they are often clinically silent until the late stages of disease. Clinical symptoms vary with the location and extent of the tumor and is related to the structures near which the tumor is growing. Skull-base chordomas often grow in the clivus. Patients with clival chordomas may present with headache, diplopia, or impairment of other cranial nerves. Depending on their size and involvement of the sella, endocrinopathy can also occur [4]. Chordomas of the mobile spine and sacrum can present with localised deep pain or radiculopathies related to the spinal level at which they occur. [13] [14] [15] [16]. Other rare presentations include epistaxis and intracranial haemorrhage [17] [18]. The diagnostic workup varies with the primary location of disease. Both computed tomography (CT) and magnetic resonance (MR) imaging are usually required for evaluation of intracranial chordomas due to bone involvement and the proximity of these tumors to many critical softtissue structures. At CT, intracranial chordoma typically appears as a centrally located, well-circumscribed, expansile soft-tissue mass that arises from the clivus with associated extensive lytic bone destruction. However, MR imaging is the single best imaging modality for both pre- and posttreatment evaluation of intracranial chordoma [19]. On CT scans, sacral chordomas show large lytic lesions centered in the midline and an associated soft-tissue mass. Calcification is present in $30 \%-70 \%$ of patients. MR Imaging can better specify the locoregional extension. Compared with skeletal muscle, typical chordomas are iso- or slightly hypointense on T1-weighted images, and typically hyperintense on T2-weighted images [20]. Bone scintigraphy shows normal or decreased distribution of the radiotracer [21]. The use of PET scan imaging in chordoma is currently under investigation. The definitive diagnosis of chordoma remains histological. The latest Word Health Organisation (WHO) of tumours of soft tissue and bone issued in 2013 distinguishes three chordoma subtypes: chordoma not otherwise specified (NOS) or "classical" or "conventional", chondroid chordoma and dedifferentiated chordoma. Later on, an additional chordoma subtype, called poorly differentiated chordoma (PDC), has been identified. Immunohistochemistry is essential for the diagnosis of chordoma. It makes it possible to make the differential diagnosis between the different types of chordoma and between chordoma and chondrosarcoma [11]. All chordomas, including the specific histologic subtypes described above, express cytokeratins and most are immunoreactive for Epithelial Membrane Antigen (EMA) and S100 protein. The most specific marker of chordoma is brachyury, a nuclear protein associated with notochord differentiation [22] [23] [24]. While expression of brachyury is highly specific for chordoma, poorly differentiated tumors and dedifferentiated areas may demonstrate 
loss of brachyury immunoreactivity [22] [23] [24] [25]. Importantly, immunoreactivity for brachyury may also be lost following decalcification and effort should always be made to procure tumoral tissue for immunohistochemistry prior to decalcification [26].

The gold standard treatment for chordomas is en-bloc excision with wide margins and postoperative external-beam radiation therapy with advanced radiation delivery techniques [7]. Surgery is the first-line treatment, but excision is often limited by adjacent critical anatomical structures. Recent progress in microsurgery has allowed improved, but not complete excision. Macroscopic postoperative tumor tissue is therefore frequent [27]. Complete surgery with negative margins achieves $70 \%$ - $80 \%$ local control [28]. However, complete excision can only be obtained in $60 \%$ to $70 \%$ of cases due to the proximity of neurological structures, the involvement of which would cause post-surgical complications [29]. Chordomas have classically been considered radioresistant. With advancement in radiation technology, effective radiation therapy doses are now able to be safely delivered. The advent of ion-based radiotherapies has made high dose radiation therapy less morbid [30]. Adjuvant high-energy photon External Beam Radiation (EBRT) therapy with doses of $60-70 \mathrm{~Gy}$ is often performed to achieve local control [31]. So far, the good results in the treatment of chordomas have been obtained with a combination of surgery and proton-based radiotherapy (PBT). Local control rates of $54 \%$ to $90 \%$ have been noted [32] [33] [34] [35]. Newer radiotherapy techniques, including stereotactic radiosurgery (SRS), and charged particle irradiation (protons (PBT), carbon ions), have been used to target the bone lesion while reducing the radiation exposure to the surrounding nerve roots and adjacents organs [36] [37]. Even for patients with unresectable spine and sacral chordomas, high-dose definitive RT using advanced techniques may achieve durable local control and disease-free survival in a subset of patients [38]. Systemic therapy for the treatment of chordomas has focused on molecularly targeted therapies. The use of cytotoxic agents has not been demonstrated to have clinically significant activity [39]. A limited number of prospective phase II studies and multiple observational series have shown significant antitumor activity with imatinib as a single agent or in combination with other drugs [40] [41]. Chemotherapy with imatinib and sorafenib shows satisfactory results by decreasing the rate of tumor growth in the chordoma [42]. Other targeted agents that may have activity include vascular endothelial growth factor (VEGF) receptor inhibitors (sunitinib, apatinib where available) and erlotinib [43] [44]. The local development of chordoma is slow with low metastatic potential $(10 \%$ of cases) [29]. The time to recurrence after surgery, whether or not followed by irradiation, varies from two to three years, but can reach ten years [29].

\section{Conclusion}

Chordoma is a rare tumor with mainly local aggression, the diagnosis of which is based on immunohistochemistry with the advent of new biomarkers. The quality 
of the surgical excision remains the main prognostic factor. Treatment is constantly evolving, especially with advances in radiotherapy and targeted therapies which have improved local control.

\section{Conflicts of Interest}

The authors declare no conflicts of interest regarding the publication of this paper.

\section{References}

[1] Collins, G., Essary, L., Strauss, J., Hino, P. and Cockerell, C.J. (2012) Incidentally Discovered Distant Cutaneous Metastasis of Sacral Chordoma: A Case with Variation in S100 Protein Expression (Compared to the Primary Tumor) and Review of the Literature. Journal of Cutaneous Pathology, 39, 637-643. https://doi.org/10.1111/j.1600-0560.2012.01895.x

[2] Rubin, A., Bagel, J. and Niedt, G. (2005) Chordoma Cutis. Journal of the American Academy of Dermatology, 52, S105-S108. https://doi.org/10.1016/j.jaad.2004.07.055

[3] Antonelli, M., Raso, A., Mascelli, S., Marco, G., Paolo, N., Antonella, C., et al. (2017) SMARCB1/INI1 Involvement in Pediatric Chordoma: A Mutational and Immunohistochemical Analysis. The American Journal of Surgical Pathology, 41, 56-61. https://doi.org/10.1097/PAS.0000000000000741

[4] Stark, A.M. and Mehdorn, H.M. (2003) Chondroid Clival Chordoma. New England Journal of Medicine, 349, e10. https://doi.org/10.1056/ENEJMicm010745

[5] Bakker, S.H., Jacobs, W.C.H., Pondaag, W., Gelderblom, H., Nout, R.A., Dijkstra, P.D.S., et al. (2018) Chordoma: A Systematic Review of the Epidemiology and Clinical Prognostic Factors Predicting Progression-Free and Overall Survival. European Spine Journal, 27, 3043-3058. https://doi.org/10.1007/s00586-018-5764-0

[6] McMaster, M.L., Goldstein, A.M., Bromley, C.M., Ishibe, N. and Parry, D.M. (2001) Chordoma: Incidence and Survival Patterns in the United States, 1973-1995. Cancer Causes \& Control, 12, 1-11. https://doi.org/10.1023/A:1008947301735

[7] Walcott, B.P., Nahed, B.V., Mohyeldin, A., Coumans, J.-V., Kahle, K.T. and Ferreira, M.J. (2012) Chordoma: Current Concepts, Management, and Future Directions. Lancet Oncology, 13, e69-e76. https://doi.org/10.1016/S1470-2045(11)70337-0

[8] Stiller, C., Trama, A., Serraino, D., Rossi, S., Navarro, C., Chirlaque, M. and Casali, P. (2013) RARECARE Working Group. Descriptive Epidemiology of Sarcomas in Europe: Report from the RARECARE Project. European Journal of Cancer, 49, 684695. https://doi.org/10.1016/j.ejca.2012.09.011

[9] Müller, H. (1858) Ueber das Vorkommen von Resten der Chorda Dorsalis bei Menschen nach der Geburt, und über ihr Verhältnis zu den Gallertgeschwulsten der Clivus. Zeitschrift fur Rationelle Medicin, 2, 202-229.

[10] Urban, J., Roberts, S. and Ralphs, J. (2000) The Nucleus of the Intervertebral Disc from Development to Degeneration. American Zoologist, 40, 53-61.

https://doi.org/10.1093/icb/40.1.53

[11] Maria Frezzaa, A., Bottab, L., Tramab, A., Dei Tos, A.P. and Stacchiottia, S. (2019) Chordoma: Update on Disease, Epidemiology, Biology and Medical Therapies. Current Opinion in Oncology, 31, 114-120. https://doi.org/10.1097/CCO.0000000000000502

[12] Chagnon, S., Vallee, C., Blery, M. and Chevrot, A. (1997) Chordome. EMC Ap. Locomoteur, 31520-A35. 
[13] Bergh, P., Kindblom, L.G., Gunterberg, B., Remotti, F., Ryd, W. and Meis-Kindblom, J.M. (2000) Prognostic Factors in Chordoma of the Sacrum and Mobile Spine: A Study of 39 Patients. Cancer, 88, 2122-2134.

https://doi.org/10.1002/(SICI)1097-0142(20000501)88:9<2122::AID-CNCR19>3.0.C O;2-1

[14] Kaiser, T.E., Pritchard, D.J. and Unni, K.K. (1984) Clinicopathologic Study of Sacrococcygeal Chordoma. Cancer, 53, 2574-2578.

https://doi.org/10.1002/1097-0142(19840601)53:11<2574::AID-CNCR2820531136> $\underline{3.0 . \mathrm{CO} ; 2-5}$

[15] Gray, S.W., Singhabhandhu, B., Smith, R.A. and Skandalakis, J.E. (1975) Sacrococcygeal Chordoma: Report of a Case and Review of the Literature. Surgery, 78, 573 582.

[16] Fourney, D.R. and Gokaslan, Z.L. (2003) Current Management of Sacral Chordoma. Neurosurg Focus, 15, 1-5. https://doi.org/10.3171/foc.2003.15.2.9

[17] Kitai, R., Yoshida, K., Kubota, T., Sato, K., Handa, Y., Kasahara, K., et al. (2005) Clival Chordoma Manifesting as Nasal Bleeding: A Case Report. Neuroradiology, 47, 368-371. https://doi.org/10.1007/s00234-005-1367-7

[18] Levi, A.D., Kucharczyk, W., Lang, A.P. and Schutz, H. (1991) Clival Chordoma Presenting with Acute Brain Stem Hemorrhage. Canadian Journal of Neurological Sciences, 18, 515-518. https://doi.org/10.1017/S0317167100032273

[19] Erdem, E., Angtuaco, E.C., Van Hemert, R., Park, J.S. and Al-Mefty, O. (2003) Comprehensive Review of Intracranial Chordomal Embryonic Origin, Clinical Manifestations, and Histopathologic Features of Intracranial Chordomas. RadioGraphics, 23, 995-1009. https://doi.org/10.1148/rg.234025176

[20] Llauger, J., Palmer, J., Amores, S., Bague, S. and Camins, A. (2000) Primary Tumors of the Sacrum: Diagnostic Imaging. American Journal of Roentgenology, 174, 417 424. https://doi.org/10.2214/ajr.174.2.1740417

[21] Rossleigh, M.A., Smith, J. and Yeh, S.D. (1986) Scintigraphic Features of Primary Sacral Tumors. Journal of Nuclear Medicine, 27, 627-630.

[22] Jambhekar, N.A., Rekhi, B., Thorat, K., Dikshit, R., Agrawal, M. and Puri, A. (2010) Revisiting Chordoma with Brachyury, a "New Age" Marker: Analysis of a Validation Study on 51 Cases. Archives of Pathology \& Laboratory Medicine, 134, 11811187.

[23] Miettinen, M., Wang, Z., Lasota, J., Heery, C., Schlom, J. and Palena, C. (2015) Nuclear Brachyury Expression Is Consistent in Chordoma, Common in Germ Cell Tumors and Small Cell Carcinomas, and Rare in Other Carcinomas and Sarcomas: an Immunohistochemical Study of 5229 Cases. The American Journal of Surgical Pathology, 39, 1305-1312. https://doi.org/10.1097/PAS.0000000000000462

[24] Vujovic, S., Henderson, S., Presneau, N., Odell, E., Jacques, T.S., Tirabosco, R., Boshoff, C. and Flanagan, A.M. (2006) Brachyury, a Crucial Regulator of Notochordal Development, Is a Novel Biomarker for Chordomas. The Journal of Pathology, 209, 157-165. https://doi.org/10.1002/path.1969

[25] Oakley, G.J., Fuhrer, K. and Seethala, R.R. (2008) Brachyury SOX-9, and Podoplanin, New Markers in the Skull Base Chordoma vs Chondrosarcoma Differential: A Tissue Microarray-Based Comparative Analysis. Modern Pathology, 21, 1461-1469. https://doi.org/10.1038/modpathol.2008.144

[26] Wasserman, J.K., Gravel, D. and Purgina, B. (2018) Chordoma of the Head and Neck: A Review. Head and Neck Pathology, 12, 261-268.

https://doi.org/10.1007/s12105-017-0860-8 
[27] Hug, E.B., Loredo, L.N., Slater, J.D., De Vries, A., Grove, R.I., Schaefer, R.A., et al. (1999) Proton Radiation Therapy for Chordomas and Chondrosarcomas of the Skull Base. Journal of Neurosurgery, 91, 432-439.

https://doi.org/10.3171/jns.1999.91.3.0432

[28] Boriani, S., Bandiera, S., Biagini, R., Bacchini, P., Boriani, L., Cappuccio, M., Chevalley, F., Gasbarrini, A., Picci, P. and Weinstein, J.N. (2006) Chordoma of the Mobile Spine: Fifty Years of Experience. Spine, 31, 493-503. https://doi.org/10.1097/01.brs.0000200038.30869.27

[29] Dauty, M., Faure, A., Le Neel, J.C., Moreau, A. and Dubois, C. (2000) Chordome Sacré: Une Pathologie Rare. Annales de Réadaptation et de Médecine Physique, 43, 84-88. https://doi.org/10.1016/S0168-6054(00)88732-2

[30] Dial, B.L., Kerr, D.L., Lazarides, A.L., Catanzano, A.A., Green, C.L., Risoli Jr., T., Blazer, D.G., Goodwin, R.C., Brigman, B.E., Eward, W.C., Larrier, N.A., Kirsch, D.G. and Mendoza-Lattes, S.A. (2020) The Role of Radiotherapy for Chordoma Patients Managed With Surgery Analysis of the National Cancer Database. SPINE, 45, E742-E751. https://doi.org/10.1097/BRS.0000000000003406

[31] Carpentier, A., Polivka, M., Blanquet, A., Lot, G. and George, B. (2002) Suboccipital and Cervical Chordomas: The Value of Aggressive Treatment at First Presentation of the Disease. Journal of Neurosurgery, 97, 1070-1077.

https://doi.org/10.3171/jns.2002.97.5.1070

[32] Terahara, A., Niemierko, A., Goitein, M., Finkelstein, D., Hug, E., Liebsch, N., et al. (1999) Analysis of the Relationship between Tumor Dose Inhomogeneity and Local Control in Patients with Skull Base Chordoma. International Journal of Radiation Oncology, Biology, Physics, 45, 351-358. https://doi.org/10.1016/S0360-3016(99)00146-7

[33] Noël, G., Feuvret, L., Calugaru, V., Dhermain, F., Mammar, H., Haie-Méder, C., et al. (2005) Chordomas of the Base of the Skull and Upper Cervical Spine. One Hundred Patients Irradiated by a 3D Conformal Technique Combining Photon and Proton Beams. Acta Oncologica, 44, 700-708. https://doi.org/10.1080/02841860500326257

[34] De Laney, T.F., Liebsch, N.J., Pedlow, F.X., Adams, J., Dean, S., Yeap, B.Y., et al. (2009) Phase II Study of High-Dose Photon/Proton Radiotherapy in the Management of Spine Sarcomas. International Journal of Radiation Oncology, Biology, Physics, 74, 732-739. https://doi.org/10.1016/j.ijrobp.2008.08.058

[35] Rutz, H.P., Weber, D.C., Sugahara, S., Timmermann, B., Lomax, A.J., Bolsi, A., et al. (2007) Extracranial Chordoma: Outcome in Patients Treated with Function-Preserving Surgery Followed by Spot-Scanning Proton Beam Irradiation. International Journal of Radiation Oncology, Biology, Physics, 67, 512-520.

https://doi.org/10.1016/j.ijrobp.2006.08.052

[36] Park, L., Delaney, T.F., Liebsch, N.J., Hornicek, F.J., Goldberg, S., Mankin, H., et al. (2006) Sacral Chordomas: Impact of High-Dose Proton/Photon-Beam Radiation Therapy Combined with or without Surgery for Primary versus Recurrent Tumor. International Journal of Radiation Oncology, Biology, Physics, 65, 1514-1521. https://doi.org/10.1016/j.ijrobp.2006.02.059

[37] Imai, R., Kamada, T., Tsuji, H., Sugawara, S., Serizawa, I., Tsujii, H., et al. (2010) Effect of Carbon Ion Radiotherapy for Sacral Chordoma: Results of Phase I-II and Phase II Clinical Trials. International Journal of Radiation Oncology, Biology, Physics, 77, 1470-1476. https://doi.org/10.1016/j.ijrobp.2009.06.048

[38] Kabolizadeh, P., Chen, Y.L., Liebsch, N., Hornicek, F.J., Schwab, J.H., Choy, E., et al. (2017) Outcome and Analysis of Tumor Response in Mobile Spine and Sacral Chor- 
doma Treated with Definitive High-Dose Photon/Proton Radiation Therapy. International Journal of Radiation Oncology, Biology, Physics, 97, 254-262.

https://doi.org/10.1016/j.ijrobp.2016.10.006

[39] Jacob, H.E. (1994) Chemotherapy for Cranial Base Tumors. Journal of Neuro-Oncology, 20, 327-335. https://doi.org/10.1007/BF01053047

[40] Stacchiotti, S., Longhi, A., Ferraresi, V., Grignani, G., Comandone, A., StuppAlexia, Bertuzzi, R., et al. (2012) Phase II Study of Imatinib in Advanced Chordoma. Journal of Clinical Oncology, 30, 914-920. https://doi.org/10.1200/JCO.2011.35.3656

[41] Stacchiotti, S., Marrari, A., Tamborini, E., Palassini, E., Virdis, E., Messina, A., et al. (2009) Response to Imatinib Plus Sirolimus in Advanced Chordoma. Annals of Oncology, 20, 1886-1894. https://doi.org/10.1093/annonc/mdp210

[42] Christopher, R. (2016) Chordoma: The Quest for Better Treatment Options. Oncology and Therapy, 4, 35-51. https://doi.org/10.1007/s40487-016-0016-0

[43] George, S., Merriam, P., Maki, R.G., Van den Abbeele, A.D., Yap, J.T., Akhurst, T. Harmon, D.C., et al. (2009) Multicenter Phase II Trial of Sunitinib in the Treatment of Nongastrointestinal Stromal Tumor Sarcomas. Journal of Clinical Oncology, 27, 3154-3160. https://doi.org/10.1200/JCO.2008.20.9890

[44] Liu, C., Jia, Q., Wei, H.F., Yang, X.H., Liu, T.L., Zhao, J., et al. (2020) Apatinib in Patients with Advanced Chordoma: A Single-Arm, Single-Centre, Phase 2 Study. Lancet Oncology, 21, 1244-1252. https://doi.org/10.1016/S1470-2045(20)30466-6 